\title{
Surface Preparation when Joining Dissimilar Steels by Adhesive Bonding
}

\author{
Anna Guzanová1, Dagmar Draganovská1 ', Miroslav Tomáš², Erik Janoško', Róbert Moro \\ Technical University of Košice, Faculty of Mechanical Engineering, Department of Technology, Materials and Computer Aided Production, Mäsiarska \\ 74, 04001 Košice \\ Technical University of Košice, Faculty of Mechanical Engineering, Department of Automotive Production, Mäsiarska 74, 04001 Košice
}

\begin{abstract}
The paper deals with the application of different types of surface preparation before the formation of glued joints made of the same and different steels. Iron phosphate, chromate-free passivation and an experimental preparation based on organosilane were tested. Deep-drawn uncoated steel DC04 and HSLA galvanized steel HX340LAD+Z were joined by adhesive bonding. When applying all types of surface preparation, the joints' strength was achieved at least at the level of the yield strength of weaker material (DC04). Surface preparation with organosilane leads to a bond strength that is close to the yield strength of a stronger material (HX340LAD+Z) and, therefore, can be recommended for bonding of steels with higher strength.
\end{abstract}

Keywords: surface preparation; adhesive bonding; dissimilar materials; shear strength

\section{Introduction}

Joining dissimilar materials is a current topic in the automotive industry. It resulted from the requirements to design tailored parts in such a way, in order to effectively utilize individual materials in the full range of their properties. The most common case of joining is joining of different grades of steels, steels with non-ferrous metals, metals with GFRP (glass fibre reinforced polymer) materials, etc., [1-3].

The joining of dissimilar materials is accompanied by certain problems that need to be solved and which result from the different material characteristics of materials to be joined. Different formability affects clinching and riveting processes, different chemical composition affects weldability of materials, etc. Joining materials by adhesive bonding makes it possible to avoid the mentioned problems. Adhesive bonding technology has been known for a long time and is still widely used for its undeniable advantages over joining materials using a joining element, which requires disruption of the continuity of the joined materials. Its effectiveness lies in the proper preparation of the surfaces, which will ensure the strongest possible bonding of the substrate and the adhesive. However, when bonding dissimilar materials, ensuring a suitable surface preparation can become a problem, especially if each of the joined materials requires a different type of surface preparation. If it were necessary to prepare the materials for adhesive bonding separately, it would be questionable whether it is economical to use this technology [4-9].

Adhesives usually require a clean and adequately roughened surface. Current alkaline degreasing agents are able to remove oil and grease from surfaces, but also to partially remove (etch) surface oxide layers which are present e.g. also on hot-dip galvanized materials, fig. 1, and thus contribute to the mechanical anchoring of the adhesive. 


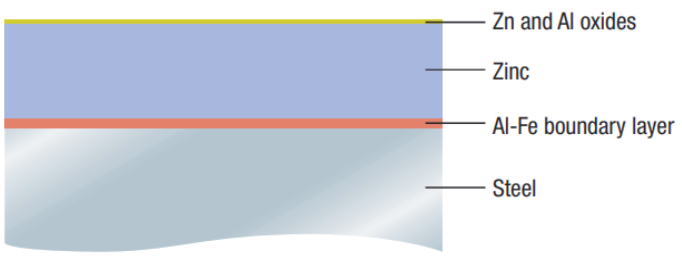

Figure 1: Surface layers on hot-dip galvanized steel.

Therefore, in the design of experimental work, the authors focused on the use of adhesive bonding technology in joining dissimilar (hot-dip galvanized and uncoated) steels using such surface preparation technologies that could be applied to both types of bonded materials simultaneously and which could positively affect bond strength and modify corrosion resistance of substrates. The load-bearing capacity of joints made of dissimilar materials was compared with the load-bearing capacity of joints made of the same materials. The strength of the joints formed with different surface preparation was compared with the strength of the joints without surface preparation.

\section{Experimental materials and methods}

\subsection{Substrate}

Two types of base materials were used for joint formation:

- uncoated steel DCO4 for deep drawing (W. Nr. 1.0338), with a thickness of $0.8 \mathrm{~mm}$ thick (hereinafter referred to as $D C$ )

- hot-dip galvanized micro alloyed steel HX340LAD + Z (W. Nr. 1.0933), with a thickness of $0.8 \mathrm{~mm}$ (hereinafter referred to as $Z N$ )

The mechanical properties of the materials and the condition of the surface upon delivery are given in Tab. 1.

Table 1: Mechanical properties of materials and surface condition on delivery.

\begin{tabular}{|l|l|l|}
\hline property & DC & ZN \\
\hline Yield strength Re [MPa] & 197 & 414 \\
\hline Ultimate tensile strength Rm [MPa] & 327 & 473 \\
\hline Elongation A80 [\%] & 39 & 28.4 \\
\hline Zn layer [g.m $\left.{ }^{-2}\right]$ & - & 111 \\
\hline Surface condition & matt & $\begin{array}{l}\text { Minimized } \\
\text { spangle, } \\
\text { improved } \\
\text { surface }\end{array}$ \\
\hline Oiled, oil weight $\left[{\left.\mathrm{g} \cdot \mathrm{m}^{-2}\right]}^{-2}\right.$ & $0.5-2.5$ & $0.6-2.5$ \\
\hline
\end{tabular}

Tab. 2 shows the chemical composition of the materials used.
Table 2: Chemical composition of the materials used, wt.\%

\begin{tabular}{|l|l|}
\hline DC & $0.04 \% \mathrm{C}, 0.25 \% \mathrm{Mn}, 0.009 \% \mathrm{P}, 0.008 \% \mathrm{~S}$ \\
\hline ZN & $\begin{array}{l}0.07 \% \mathrm{C}, 0.6 \% \mathrm{Mn}, 0.007 \% \mathrm{Si}, 0.016 \% \mathrm{P}, 0.007 \% \mathrm{~S}, \\
0.025 \% \mathrm{Nb}, 0.001 \% \mathrm{Ti}\end{array}$ \\
\hline
\end{tabular}

The test specimens for adhesive joints formation with dimensions of $100 \times 25 \mathrm{~mm}$ were made of steel sheets by cutting.

\subsection{Surface preparation}

The following types of surface preparation before adhesive joining were tested:

- no surface preparation - for adhesive joining the material was used as delivered. The manufacturer states that the sheet is preserved by electrostatic oiling with an oil weight of $0.5-2.5 \mathrm{~g} . \mathrm{m}^{-2}$.

- surface treated with chromate-free zirconate passivation - the chromate-free passivation process usually follows the phosphating of steel by all types of phosphating baths. It does not contain chromium ions or other environmentally harmful substances. The product also passivates active surfaces of unphosphated steel, aluminum and magnesium alloys, zinc coatings after degreasing or otherwise activated metal surfaces. It can also be used as a conversion layer before coating, or adhesive joining. The procedure of chromate-free zirconate passivation was as follows: degreasing, rinsing, zirconate passivation (RT, 3 min), rinsing, rinsing in demi water, drying.

- surface with a layer of iron phosphate - the process of iron phosphating creates a very compact coating of iron phosphate on steel with an average coating weight of $0.5 \mathrm{~g} \cdot \mathrm{m}^{-2}$. The procedure of the phosphating process was as follows: degreasing, rinsing, phosphating (60 ${ }^{\circ}$, $\left.3 \mathrm{~min}\right)$, rinsing, rinsing in demi water, drying.

- surface treated with organosilane - this is an experimental agent to increase the adhesion of organic coatings. When using the agent, it is assumed that the organic functional groups in organosilane will create the chemical bond with the organic binder of the paint and thus increase its adhesion to the substrate. Since the binder base is the same for many organic paints and adhesives (e.g. epoxy-based paints and adhesives), we expect to increase the strength of adhesive joints even when applied under adhesive. The procedure of organosilane application was as follows: degreasing, rinsing, immersion in an aqueous solution of the organosilicate preparation (RP, 10 min), drying.

\subsection{Surface roughness}

To assess the effect of surface microgeometry on the strength of adhesive joints, the surface roughness of base materials was measured, as well as the roughness of passivated, phosphated materials and materials treated with organosilane agent. The microgeometry of the sample surfaces was evaluated using a contact profilometer Surftest SJ-201, Mitutoyo, Japan. It is a stylus profilometer, which works on the principle of copying the evaluated surface by a probe terminated with 
a diamond tip with a radius of curvature of 2 $\mu \mathrm{m}$, placed on a sprung arm. The sharp tip of the profilometer converts peaks and valleys on the surface into mechanical movement, which is then processed into an electrical signal and further interpreted as a numerical value of a specific surface roughness parameter, or as a graphical record of the surface roughness profile - profilogram. The roughness of the materials was assessed according to ISO 4287 using the parameters Ra (arithmetical mean deviation of the measured profile), Rz (maximum height of profile at the basic length), RSm (mean width of the profile elements), nonnormalized value RPc (the mean number of peaks per centimetre) and finally by Abbot Firestone material ratio curve of the profile. The mean value of the five measurements performed on each material was calculated. A profilograms of the individual surfaces were also recorded.

\subsection{Corrosion resistance of materials}

Potentiostat SP-150, BioLogic, Seyssinet-Pariset, Francewas usedforcorrosion tests. The measurement was performed using a three-electrode connection (Fig. 2), where the working electrode is a material to be measured, the saturated calomel electrode served as a reference electrode, and the auxiliary electrode was a platinum electrode. The tests were performed at room temperature, with a measured area of $0.636 \mathrm{~cm}^{2}$. A $3.5 \% \mathrm{NaCl}$ solution was used in the experiment as an electrolyte, commonly used in corrosion tests to simulate an aggressive corrosive environment.

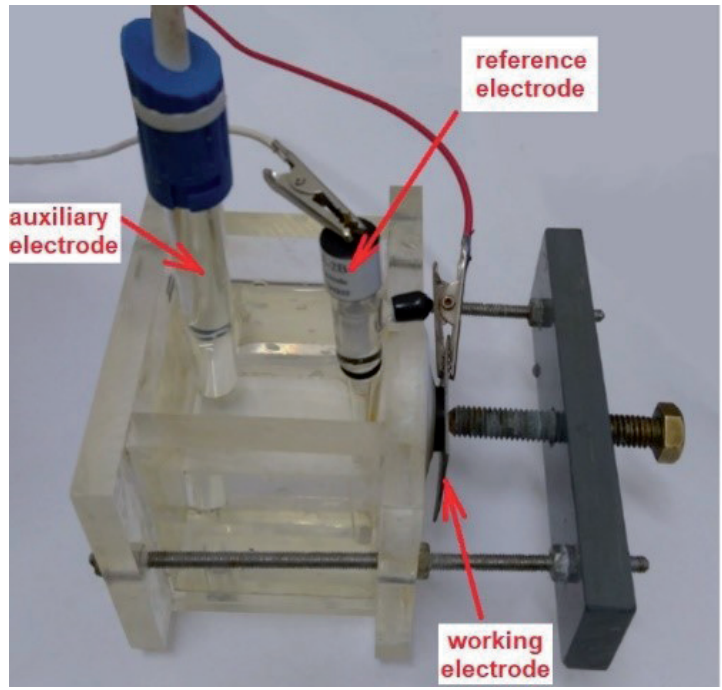

Figure 2: Three-electrode connection used for corrosion tests.
Preparation of the original DC and ZN materials for measurement consisted of degreasing and subsequent rinsing with demineralized water. When measuring materials with applied passivator, phosphate or organosilane, no surface treatment was performed before corrosion tests.

Each test began with a stabilization period (rest time) that lasted 60 minutes. This was followed by potentiostatic electrochemical impedance spectroscopy (PEIS) at frequencies from $100 \mathrm{kHz}$ to $10 \mathrm{mHz}$, using a sinusoidal amplitude of $10 \mathrm{mV}$. The number of frequencies per decade was 10 (a total of 51 different frequencies). The measurement results were displayed using a Nyquist plot, Fig. 3a. An equivalent circuit shown in Fig. 3b was used to analyse the measured results for the uncoated DC material. Since the reaction of the electrolyte with the surface of the material showed one impedance loop, the resistance $\mathrm{R} 1$ represents the resistance of the electrolyte, $\mathrm{R} 2$ represents the resistance of the material (polarization resistance Rp) and Q2 represents the variable capacitance created at the electrolyte-material interface.

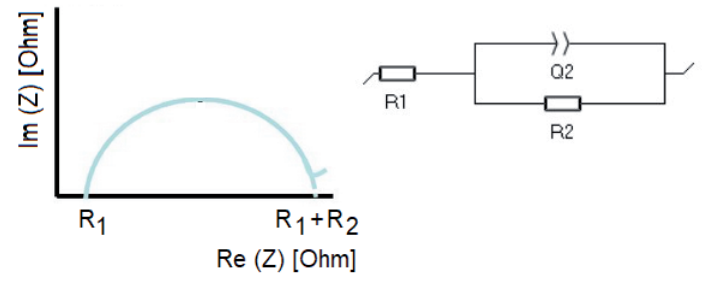

Figure 3: a) Nyquist plot and b) equivalent circuit used for DC material.

For the hot-dip galvanized ZN material, an equivalent circuit, shown in Fig. 4b, was used. Resistance R1 represents the resistance of the electrolyte, $R 2$ represents the resistance of the zinc layer, R3 represents the resistance of the steel base below the zinc layer, Q1 represents the variable capacitance created between the electrolyte and the $\mathrm{Zn}$ layer, $\mathrm{C} 3$ represents the capacitance between the $\mathrm{Zn}$ layer and the base material. The output of this test is shown as a Nyquist plot (Fig. 4a) from which the resistances of electrolyte and material were determined using an equivalent circuit.

The final measurement was linear polarization $(L P)$, where we polarized the material first in the direction of the anodic and then the cathodic reaction starting from the equilibrium potential, which was obtained after the stabilization phase. 


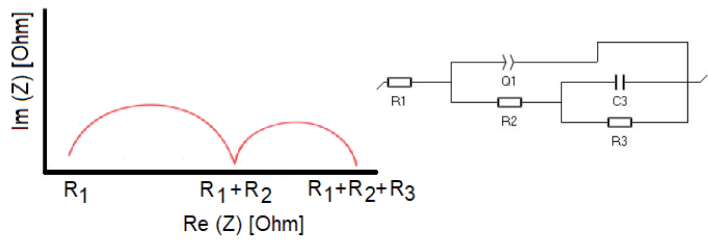

Figure 4: a) Nyquist plot and b) equivalent circuit used for ZN material.

Polarization was performed in the voltage range from $-200 \mathrm{mV}$ to $+200 \mathrm{mV}$ from the corrosion potential (Ecorr) with a scan rate of $0.2 \mathrm{mV} \cdot \mathrm{s}^{-1}$. The results of this test were shown as a Tafel plot from which the corrosion potential Ecorr, the corrosion current icorr, the Tafel constants ba and bc and the corrosion rate rcorr were determined, Fig. 5.

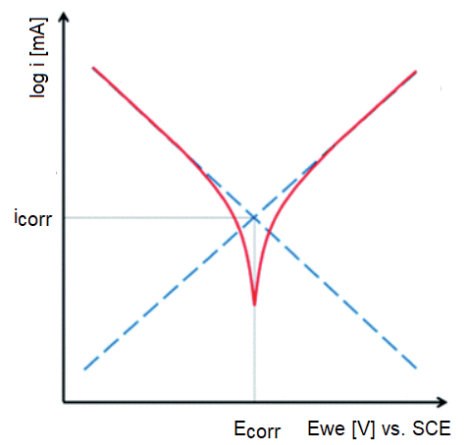

Figure 5: Tafel plot.

\subsection{Adhesive and adhesive bonding}

Heat curing solvent free one-component high crash resistant structural adhesive based on toughened epoxy resin, specially developed to provide high peel and impact peel resistance over a wide temperature range, performs well to typical torsional and crash forces was used to create the joints. It is primarily intended for the automotive industry. It has good adhesion to galvanized substrates, Zn-Mg alloys and aluminium alloys used in the automotive industry, where high strength and corrosion protection are required. The tensile strength of the adhesive is $35 \mathrm{MPa}$, the shear strength according to DIN EN 1465 at $23^{\circ} \mathrm{C}$ is $>30$ $\mathrm{MPa}$. The working range of the adhesive is from - 40 to $90^{\circ} \mathrm{C}$.

Single lap joints were formed according to DIN EN 1465, with a bond length of $12.5 \mathrm{~mm}$, Fig. 6. Curing of the adhesive took place in an electric furnace at $180^{\circ} \mathrm{C}, 30 \mathrm{~min}$.

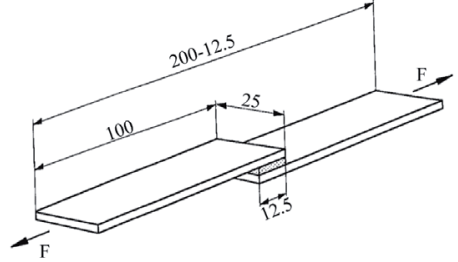

Figure 6: Geometry of a single lap joint.

For each type of surface preparation, 15 joints were made according to the following key: five joints of DC-DC, five joints of ZN-ZN, five joints of DC-ZN. The average joint strength was calculated as the average of five measurements for each type of joint (material combination) and surface preparation method.

Determination of tensile lap-shear strength of bonded joints was performed on a TiraTest 2300 tensile machine at a crosshead movement speed of $10 \mathrm{~mm} \cdot \mathrm{min}^{-1}$. The device allows continuous recording of load and crosshead displacement and records the maximum force when breaking the joint. Subsequently, the type of joint failure was visually determined (adhesive - separation of the adhesive from the substrate, cohesive -fracture in the adhesive layer, or mixed, Fig. 7). From the graphical record of the load and movement of the crosshead, can be find out some properties of the adhesive (toughness), possible plastic deformation of the substrate and the overall course of the test.

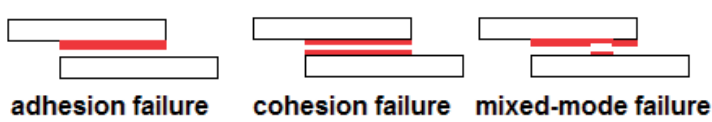

Figure 7: Failure mode of adhesive joints.

\section{Results and discussion}

\subsection{Surface roughness}

The roughness of individual materials determined using selected parameters is given in Tab. 3 and the corresponding profilograms are shown in Fig. 8 and 9.

Tab. 3 shows that the value of the parameter Ra does not change significantly for individual materials and surface treatments, it varies for DC material from 0.87 to $0.98 \mu \mathrm{m}$, for ZN material from 0.62 to $1 \mu \mathrm{m}$. The $\mathrm{Rz}$ parameter is also relatively stable, ranging from 4.66 to $5.86 \mu \mathrm{m}$ for DC material and from 4.03 to $5.29 \mu \mathrm{m}$ for ZN material. However, the differences between the individual surface treatments were 
Table 3: Roughness of evaluated surfaces.

\begin{tabular}{|l|l|l|l|l|}
\hline & $\begin{array}{l}\text { Ra } \\
{[\mu \mathrm{m}]}\end{array}$ & $\begin{array}{l}\mathrm{Rz} \\
{[\mu \mathrm{m}]}\end{array}$ & $\begin{array}{l}\mathrm{RSm} \\
{[\mu \mathrm{m}]}\end{array}$ & $\begin{array}{l}\mathrm{RPC} \\
{\left[\mathrm{cm}^{-1}\right]}\end{array}$ \\
\hline DC - original surface & 0.87 & 5.12 & 300.3 & 34.2 \\
\hline DC - passivation & 0.98 & 5.82 & 246.8 & 41.46 \\
\hline DC - iron phosphate & 0.96 & 5.86 & 280.0 & 35.83 \\
\hline DC - organosilane & 0.94 & 4.66 & 256.8 & 39.86 \\
\hline ZN - originalsurface & 1.00 & 5.11 & 137.8 & 73.76 \\
\hline ZN - passivation & 0.75 & 4.82 & 89.0 & 112.38 \\
\hline ZN - iron phosphate & 0.96 & 5.29 & 99.6 & 101.42 \\
\hline ZN - organosilane & 0.62 & 4.03 & 83.0 & 120.94 \\
\hline
\end{tabular}

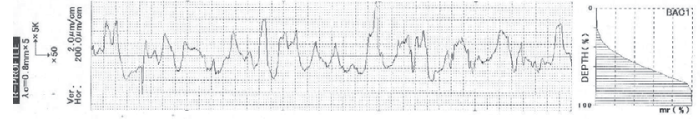

DC original

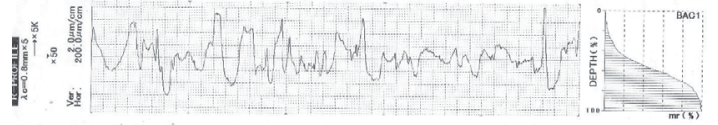

DC passivation

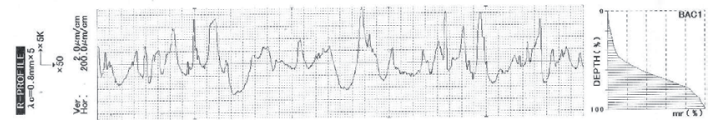

DC iron phosphate

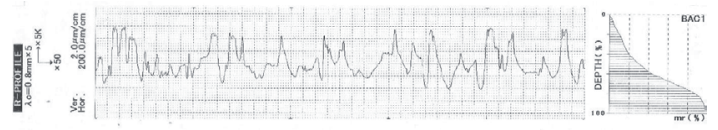

DC organosilane

Figure 8: Profilograms of original and modified DC material.

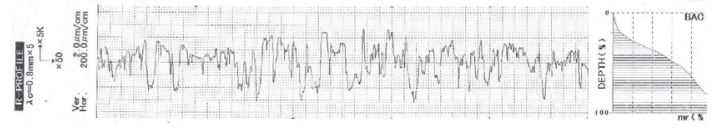

ZN original

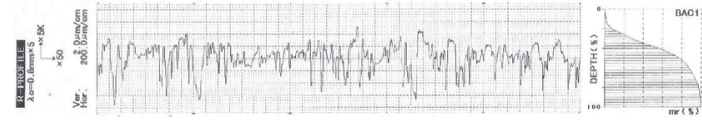

ZN passivation

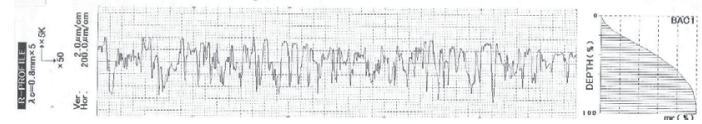

ZN iron phosphate

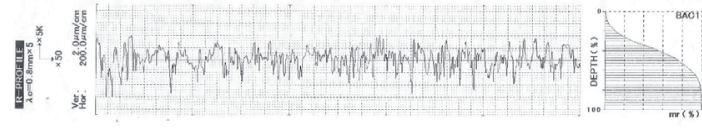

ZN organosilane

Figure 9: Profilograms of original and modified ZN material. more clearly reflected in other parameters - RSm and RPc. The number of peaks per centimeter of base length (RPc) increased for all treated surfaces compared to the original surface. For DC material, RPc increased only slightly, a more significant increase occurred for ZN material. An increase in the number of peaks indicates an increase in the contact area between the adhesive and the chemically treated surface. The increase in the contact area should be reflected in an increase in the strength of the joints, but this only applies if the adhesion of the formed passivation, phosphate or organosilane layer to the substrate exceeds the adhesion of the adhesive to this layer. In the case of DC material, the number of peaks on the surface increased the most after surface passivation, in the case of ZN material after application of the organosilane layer and after passivation. The parameter RSm, which evaluates the mean width of the profile elements, is a reciprocal of the RPc parameter, therefore, for the measured surfaces, it exhibits the opposite course.

The differences in the surface morphology of DC materials can be seen in more detail from the profilograms shown in Fig. 8.

It can be seen from the profilograms that the change in the surface morphology of the DC material after individual surface treatments is minimal, Fig. 8. The surfaces after passivation and application of the organosilane only copy the original surface of the DC material. The surface after iron phosphating is amorphous in nature and copies the original surface of the sheet as well.

The material bearing area ratio, represented by the Abbot Firestone material ratio curve of the profile, is also an apt criterion for evaluating surfaces with predominantly concave or convex irregularities. The surfaces of the DC material show a relatively small material bearing area ratio at the level of the mean line of the primary profile. The change in the Abbot Firestone curve of the individual treated surfaces of the $D C$ material is insignificant.

The differences in the surface morphology of ZN materials can be seen in more detail from the profilograms shown in Fig. 9.

In the case of ZN material, after all chemical surface treatments, there was a clear increase in the number of peaks compared to the untreated state, Fig. 9. However, it should be emphasized that the ZN material had twice the number of peaks compared to the $D C$ material already in the original state. After 
chemical surface treatments, the numbers of peaks are significantly higher compared to DC material treated with the same surface treatment. The surface of the original ZN material shows a relatively large material bearing area ratio at the level of the mean line of the primary profile, after chemical treatments the ratio of bearing area of the material at a given level increased even more.

The shape of the Abbot-Firestone curve is different for both materials in the original state. The DC material exhibits a more convex character of surface irregularities, similar to Fig. 10a, while the ZN material shows a rather concave character surface irregularities, similar to Fig. 10b.
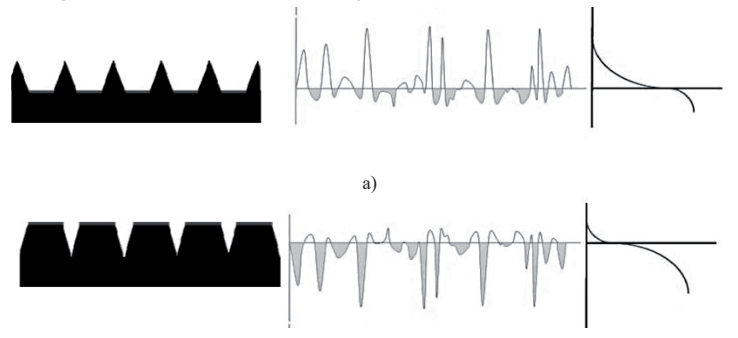

Figure 10: Different character of irregularities of two surfaces with the same Ra value.

It follows from the above findings that in terms of microgeometry and the size of the contact area between the material and the adhesive, the ZN material and its modified variants have a greater presumption to create a joint with a higher loadbearing capacity than the DC material.

\subsection{Corrosion resistance of chemically treated materials}

\subsubsection{Potentiostatic EIS of DC material}

The results of the potentiostatic EIS for the original DC material as well as its surface-treated variants can be found in Fig. 11 and in Tab. 4.

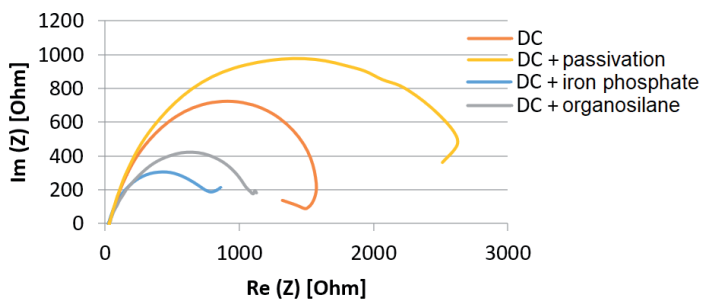

Figure 11: Nyquist plot of the original DC material and its surface treated variants.

The capacitive loop of the original DC material is the base against which the corrosion resistance of the other surface-treated variants of the DC material will be compared. The diameter of the capacitive loops corresponds to the polarization resistance of the material (R2), while the distance of the loop from the beginning of the $\mathrm{x}$-axis corresponds to the resistance of the electrolyte (R1). Since the same electrolyte with the same resistance was used in all measurements, the loops start on the $x$-axis from the same starting point. A larger loop diameter indicates greater material resistance, which means greater corrosion resistance and vice versa. Fig. 11 shows that the DC material treated with zirconate passivation shows an increased polarization resistance and thus a higher corrosion resistance compared to the original DC material. On the contrary, surfaces with iron phosphate and organosilane have a significantly lower polarization resistance and thus a lower corrosion resistance compared to the original DC material. In percentage terms, the corrosion resistance of the phosphated surface decreased by $50 \%$, and the surface with the organosilane layer by $32 \%$ compared to the original DC material, while the resistance of the surface with chromate-free passivation increased by $60 \%$, Tab. 4.

Table 4: Results of EIS analysis of DC material and its surface treated variants

\begin{tabular}{|l|l|l|l|l|}
\hline material & $\begin{array}{l}\mathrm{R}_{1} \\
{[\mathrm{Ohm}]}\end{array}$ & $\mathrm{R}_{2}[\mathrm{Ohm}]$ & $\begin{array}{l}\mathrm{Q}_{2} \\
{\left[\mathrm{e}^{-3} \mathrm{~F} \cdot \mathrm{s}^{(\mathrm{a}-1)}\right]}\end{array}$ & $\mathrm{a}^{2}$ \\
\hline $\begin{array}{l}\text { DC- } \\
\text { original }\end{array}$ & $27.9 \pm 1$ & $1662 \pm 42$ & $0.39 \pm 0.01$ & $0.83 \pm 0.01$ \\
\hline $\begin{array}{l}\mathrm{DC}- \\
\text { passivated }\end{array}$ & $24.9 \pm 4$ & $2669 \pm 116$ & $0.37 \pm 0.05$ & $0.79 \pm 0.01$ \\
\hline $\begin{array}{l}\text { DC - iron } \\
\text { phosphate }\end{array}$ & $29.1 \pm 5$ & $841.2 \pm 58$ & $0.48 \pm 0.18$ & $0.81 \pm 0.06$ \\
\hline $\begin{array}{l}\text { DC - } \\
\text { organosilane }\end{array}$ & $27.2 \pm 6$ & $1139 \pm 73$ & $0.84 \pm 0.19$ & $0.76 \pm 0.06$ \\
\hline
\end{tabular}

\subsubsection{Potentiostatic EIS of ZN material}

The results of the potentiostatic EIS for the ZN material and its surface-treated variants can be found in Fig. 12 and in Tab. 5. The capacitive loop of the original ZN material is the base against which the surface-treated variants of the ZN material will be compared. For galvanized material, the measured curves consist of two capacitive loops with different diameters, the diameter of the first loop corresponds to the polarization resistance of the zinc layer and the diameter of the second loop to the polarization resistance of the steel base material. As is evident from Fig. 12, the capacitive loops of all surfacetreated ZN materials have a higher polarization 
resistance than the original ZN material. Thus, each surface modification had a positive effect on the corrosion resistance of the $\mathrm{ZN}$ material.

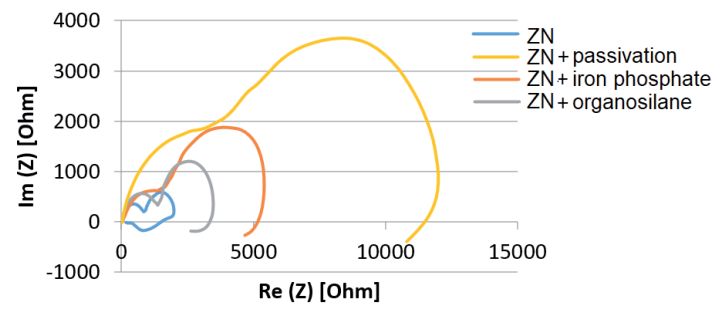

Figure 12: Nyquist plot of the original ZN material and its surface treated variants.

In percentage terms, the increase of polarization resistance and thus the corrosion resistance of individual surface treatments of $\mathrm{ZN}$ material compared to the original ZN material was as follows: phosphated surface showed an increase by $138 \%$, surface treatment with organosilane by $50 \%$ and surface treated with chromate-free zirconate passivation by up to $388 \%$, Tab. 5 .

3.2.3 Linear polarization of $D C$ material

Corrosion potential (Ecorr) and corrosion current (icorr) are two important parameters from which the corrosion resistance of materials is determined. The higher the corrosion current and the more negative the corrosion potential, the worse the corrosion resistance of the material.

Corrosion potential Ecorr of original material DC, Fig. 13 and Tab. 6, was $-686 \mathrm{mV}$. The DC materials treated with iron phosphating and organosilane had a more negative Ecorr value than the original DC material, $-702 \mathrm{mV}$ and $-746 \mathrm{mV}$ respectively, i.e. their corrosion resistance deteriorated compared to the original DC material. For the material treated with chromate-free zirconate passivator, the Ecorr was $-665 \mathrm{mV}$, which is a value more positive than the original DC material - this treatment improved the corrosion resistance of the material.

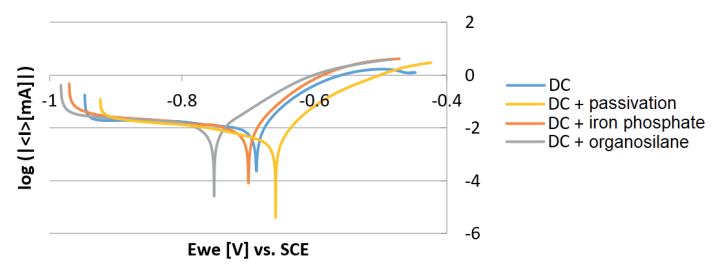

Figure 13: Linear polarization curves for DC material and its surface treated variants.

Table 6 shows the results of linear polarization processed by Tafel analysis. The corrosion rate for the DC material treated with iron phosphating and organosilane is similar, higher than the corrosion rate of the original DC material. The corrosion rate of the DC material with chromium-free passivation is lower than the corrosion rate of the original DC material.

\subsubsection{Linear polarization of ZN material}

Fig. 14 shows the polarization curve of the ZN material and its surface-treated variants. Corrosion potential for individual surface treatments of ZN material are listed in Tab. 7. Intersection of tangents to strongly linear areas cannot be found, Fig. 14. Therefore, these measurements cannot be evaluated using Tafel analysis.

All chemically modified variants of the ZN material have a more positive Ecorr compared to the original $\mathrm{ZN}$ material. This means that all surface treatments have a positive impact on the corrosion resistance of the $\mathrm{ZN}$ material. It would

Table 5: Results of EIS analysis of ZN material and its surface treated variants.

\begin{tabular}{|l|l|l|l|l|l|}
\hline material & $\mathrm{R}+[\mathrm{Ohm}]$ & $\mathrm{R}_{2}[\mathrm{Ohm}]$ & $\mathrm{R}_{3}[\mathrm{Ohm}]$ & $\mathrm{Q}_{1}\left[\mathrm{e}^{-3} \mathrm{~F} \cdot \mathrm{s}\left(\mathrm{a}^{-1}\right)\right]$ & $\mathrm{C}_{3}\left[\mathrm{e}^{-3} \mathrm{~F}\right]$ \\
\hline ZN -original & $26.7 \pm 1$ & $889 \pm 5$ & $1158 \pm 58$ & $0.39 \pm 0.01$ & $0.74 \pm 0.01$ \\
\hline ZN - passivated & $26.1 \pm 1$ & $4342 \pm 574$ & $8027 \pm 1328$ & $10.69 \pm 1.09$ & $0.108 \pm 0.01$ \\
\hline ZN-iron phosphate & $23.1 \pm 1$ & $2118 \pm 269$ & $3213 \pm 32$ & $0.48 \pm 0.18$ & $0.23 \pm 0.01$ \\
\hline ZN-organosilane & $29.4 \pm 6$ & $1336 \pm 136$ & $2152 \pm 4$ & $9.27 \pm 2$ & $0.53 \pm 0.01$ \\
\hline
\end{tabular}

Table 6: Results of Tafel analysis of DC material and its surface treated variants.

\begin{tabular}{|l|l|l|l|l|l|}
\hline material & Ecorr $[\mathrm{mV}]$ & Icorr $[\mathrm{uA}]$ & ba $[\mathrm{mV}]$ & bc $[\mathrm{mV}]$ & rcorr $[\mathrm{mmpy}]$ \\
\hline DC - original & $-686 \pm 4$ & $13 \pm 0.1$ & $60 \pm 5$ & $1726 \pm 71$ & $0.023 \pm 0.002$ \\
\hline DC - passivated & $-665 \pm 5$ & $7.15 \pm 0.1$ & $64 \pm 2$ & $541 \pm 17$ & $0.019 \pm 0.001$ \\
\hline DC - iron phosphate & $-702 \pm 3$ & $9 \pm 0.7$ & $50 \pm 5$ & $393 \pm 53$ & $0.033 \pm 0.001$ \\
\hline DC - organosilane & $-746 \pm 1$ & $11.97 \pm 0.1$ & $73 \pm 5$ & $625 \pm 166$ & $0.031 \pm 0.001$ \\
\hline
\end{tabular}




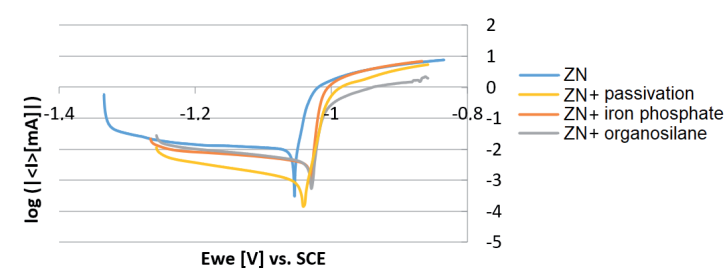

Figure14: Linear polarization curves for ZN material and its surface treated variants.

be appropriate to repeat the test with a longer rest time of materials in the electrolyte before the test for successful implementation of the Tafel analysis.

Table 7: Corrosion potential Ecorr of ZN material and its surface treated variants

\begin{tabular}{|l|l|}
\hline material & Ecorr $[\mathrm{mV}]$ \\
\hline ZN - original & $-1058 \pm 5$ \\
\hline ZN - passivated & $-1038 \pm 4$ \\
\hline ZN - iron phosphate & $-1031 \pm 1$ \\
\hline ZN - organosilane & $-1032 \pm 4$ \\
\hline
\end{tabular}

The results of the evaluation of the corrosion resistance of both basic materials and their surface-treated variants were confirmed by two independent measuring methodologies - linear polarization and potentiostatic EIS.

\subsection{Strength of adhesively bonded joints}

The load-bearing capacity of adhesive joints was calculated according to formula (1):

$$
\text { load capacity }[\mathrm{MPa}]=\frac{\text { load at fracture }[\mathrm{N}]}{\text { bonded area }\left[\mathrm{mm}^{2}\right]}(1)
$$

The bonded area is $12.5 \times 25 \mathrm{~mm}$, totally $312.5 \mathrm{~mm}^{2}$. Tab. 8 shows the maximum load at fracture in $\mathrm{N}$ and the calculated load-bearing capacity of the joints in MPa as the average of five measurements.

Fig. 15 shows course of loading at tensile lapshear test of bonded joints. Tab. 9 shows failure mode of tested assemblies.

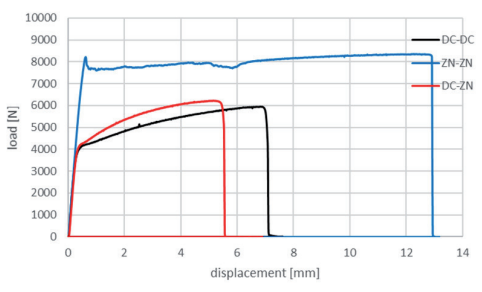

a) no preparation (oiled)

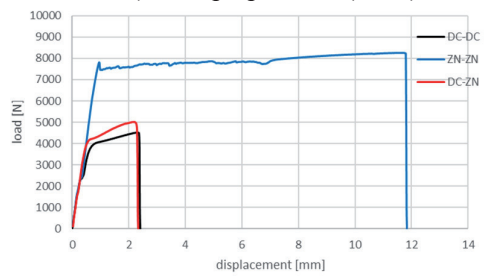

b) passivation

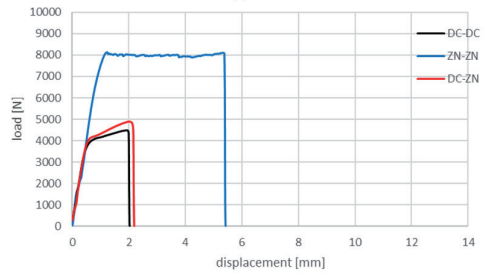

c) iron phosphate

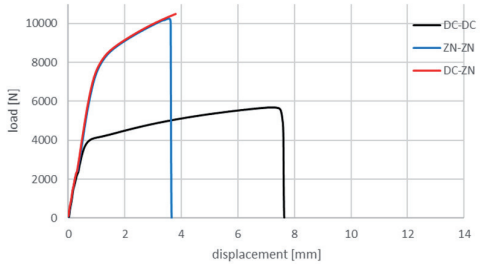

d) organosilane

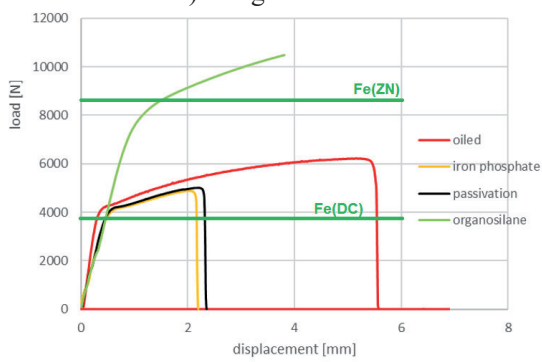

e) hybrid DC-ZN joints

Figure 15: Load-displacement curves of single-lap adhesive joints.

Table 8: Load at fracture and load-bearing capacity of joints.

\begin{tabular}{|l|l|l|l|l|l|l|}
\hline Surface treatment & \multicolumn{3}{l}{ Load at fracture $[N]$} & \multicolumn{2}{l|}{ Load-bearing capacity [MPa] } \\
\hline & DC-DC & ZN-ZN & DC-ZN & DC-DC & ZN-ZN & DC-ZN \\
\hline no & 5948 & 8363 & 6252 & 19.0 & 26.8 & 20.0 \\
\hline passivation & 4499 & 8206 & 4924 & 14.4 & 26.3 & 15.8 \\
\hline iron phosphate & 4478 & 8494 & 4884 & 14.3 & 27.2 & 15.6 \\
\hline organosilane & 5677 & 10327 & 6122 & 18.2 & 33.0 & 19.6 \\
\hline
\end{tabular}


The following findings follow from Fig. 15: when the joints are loaded, plastic deformation of the substrate with lower strength (DCO4) occurs. On all load curves of the DC-DC and DC-ZN joints, a break is evident, separating the line and curve part of the dependence, and this still occurs at the same load force. This force corresponds to the force at the yield point of material DC04. If, according to the metallurgical certificate of the material DC04, its yield strength $\mathrm{Re}=197 \mathrm{MPa}$, then the force corresponding to the yield strength is calculated for the given cross section of test sample A according to the relation (2):

$$
F_{e}=R_{e} \times A=R_{e} \times b \times h[N],
$$

where $b$ is the width of the sample $(25 \mathrm{~mm})$ and $h$ is the thickness of the sheet $(0.8 \mathrm{~mm})$. After substituting the yield strength of the DC material, we can find the value of force corresponding to the yield strength $\mathrm{Fe}$ $(D C)=3940 \mathrm{~N}$. Similarly, we can calculate the force corresponding to the yield strength for the material $\mathrm{ZN}$, when yield strength is known ( $\mathrm{Re}=414 \mathrm{MPa})$, and thus Fe $(Z N)=8280 \mathrm{~N}$. Proper joint operation means that no plastic deformation of the substrates occurs. Permanent deformation of the substrate is a limit state that would prevent the joint from functioning. In this respect, any surface treatment that exhibits a load at fracture at the level of max. $3940 \mathrm{~N}$ is satisfactory, i.e. satisfactory load-bearing capacity was shown by each of the tested surface treatments of the substrates, Fig. $15 \mathrm{~g}$.

Furthermore, the following characteristic behaviour of materials and joints is evident from the load-displacement curves (Fig. 15):

ZN-ZN joints achieved the highest strength in all types of surface preparation. This was manifested by an increase in the loading force up to the level of the yield strength of microalloyed steel $\mathrm{Fe}(\mathrm{ZN})$, stabilization at this force on a relatively large displacement of cross-head 5-13 mm and finally failure of the joint. During the steady force phase, plastic deformation of the substrate and elastic deformation of the adhesive took place simultaneously. The failure of the ZN-ZN joints was cohesive, or adhesive-cohesive with a predominance of cohesive failure, Fig. 5. Bonding of the adhesive was best directly on the substrate (oiled) as well as on the surface treated with chromium-free passivation, which was reflected in the cohesion of the joint to large values of displacement (11-13 $\mathrm{mm})$. For the phosphated surface, the joints failed at a displacement of about $5 \mathrm{~mm}$, for the organosilane about $3.5 \mathrm{~mm}$. The value of displacement thus probably corresponds to the binding energy of the adhesive to the formed surface layer, or surface layer to the substrate, and this ultimately limits the loadbearing capacity of the joint itself.

DC-DC joints had lower strength compared to ZNZN joints. The loading also shows a characteristic course - an increase in force to a value corresponding to the yield strength of deep-drawn material Fe(DC), followed by plastic deformation of the substrate accompanied by strengthening to a limit value corresponding to adhesion of the adhesive to the substrate or surface layer formed on the substrate, or the bonding forces of the layer formed during surface preparation to the substrate. This is also confirmed by the failure modes of the joints, shown in Tab. 9, which were mostly adhesive (passivation, phosphate, organosilane). Joints with no surface preparation failed with adhesive-cohesion failure mode. The joints that broke at the highest values of displacement - joints with no surface preparation and joints with organosilane surface treatment (displacement $7 \mathrm{~mm}$ ) have the best adhesion of the adhesive to the substrate.

DC-ZN joints are characterized by the fact that under load they copy the behaviour of a less strong joint material, i.e. DC steel. Mixed joints reach the parameters of DC-DC joints - they have a similar load-bearing capacity and displacement values at the moment of connection failure. Joints with no surface treatment remain cohesive up to displacement value of $5 \mathrm{~mm}$, joints with passivation layer and phosphate fail even at a displacement of $2 \mathrm{~mm}$. A notable exception comprises mixed joints with a layer of organosilane, where the behaviour of the joint, on the contrary, copies the behaviour of the stronger from the pair of joined materials. The loadbearing capacity of these joints exceeds the loadbearing capacity of ZN-ZN joints with organosilane and exceeds the value of $10 \mathrm{kN}$. This value already extends to the level of the shear strength of the adhesive (the manufacturer states > $30 \mathrm{MPa}$, which corresponds to a force of $>9375 \mathrm{~N}$ over an overlap area of $25 \times 12.5 \mathrm{~mm}$ ). If the adhesion of the adhesive to the substrate reaches the level of shear strength of the adhesive itself - the properties of the adhesive can be used to the maximum extent. This is exactly what happened during the preparation of 
substrates with organosilane. The failure mode of the mixed joints was mainly adhesive or adhesivecohesive with a predominance of adhesive failure, while the adhesive was always separated from the DC substrate, which generally proved poorer adhesion to the adhesive.

Tab. 9 also shows that in the case of mixed adhesion-cohesion failure, the adhesive failure occurred preferably at the edges of the joint, at the places with the highest values of shear and peel stresses, Fig. 16
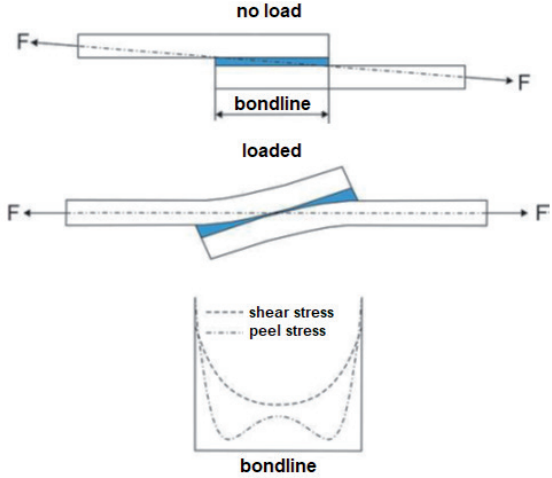

Figure 16: Course of shear and peel stress along bondline.

Table 9: Failure modes of joints tested.
A summary graph of the load-bearing capacity of dissimilar joints achieved with individual treatments of joined surfaces is shown in Fig. 17.

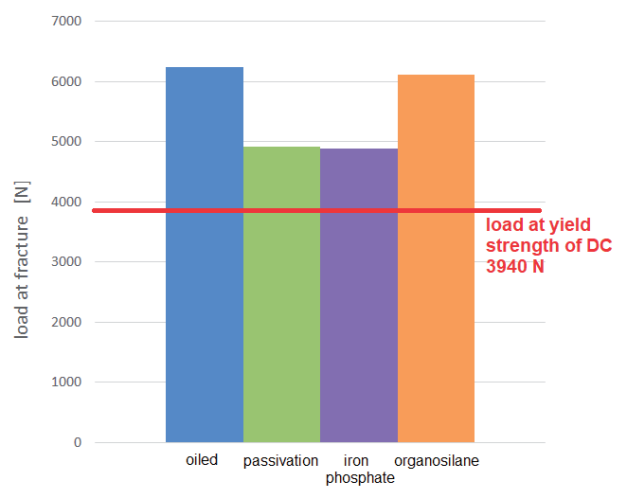

Figure 17: Load-bearing capacity of adhesive joints of dissimilar materials with different surface treatments.

Fig. 17 shows that the strength of joints made of dissimilar materials with different chemically treated surfaces in all cases exceeds the yield strength of the material with lower strength (DC). It is not necessary to achieve a higher load-bearing capacity of the joints, because plastic deformation of the low strength material would occur, which can be considered as the limit state of the adhesive joint.

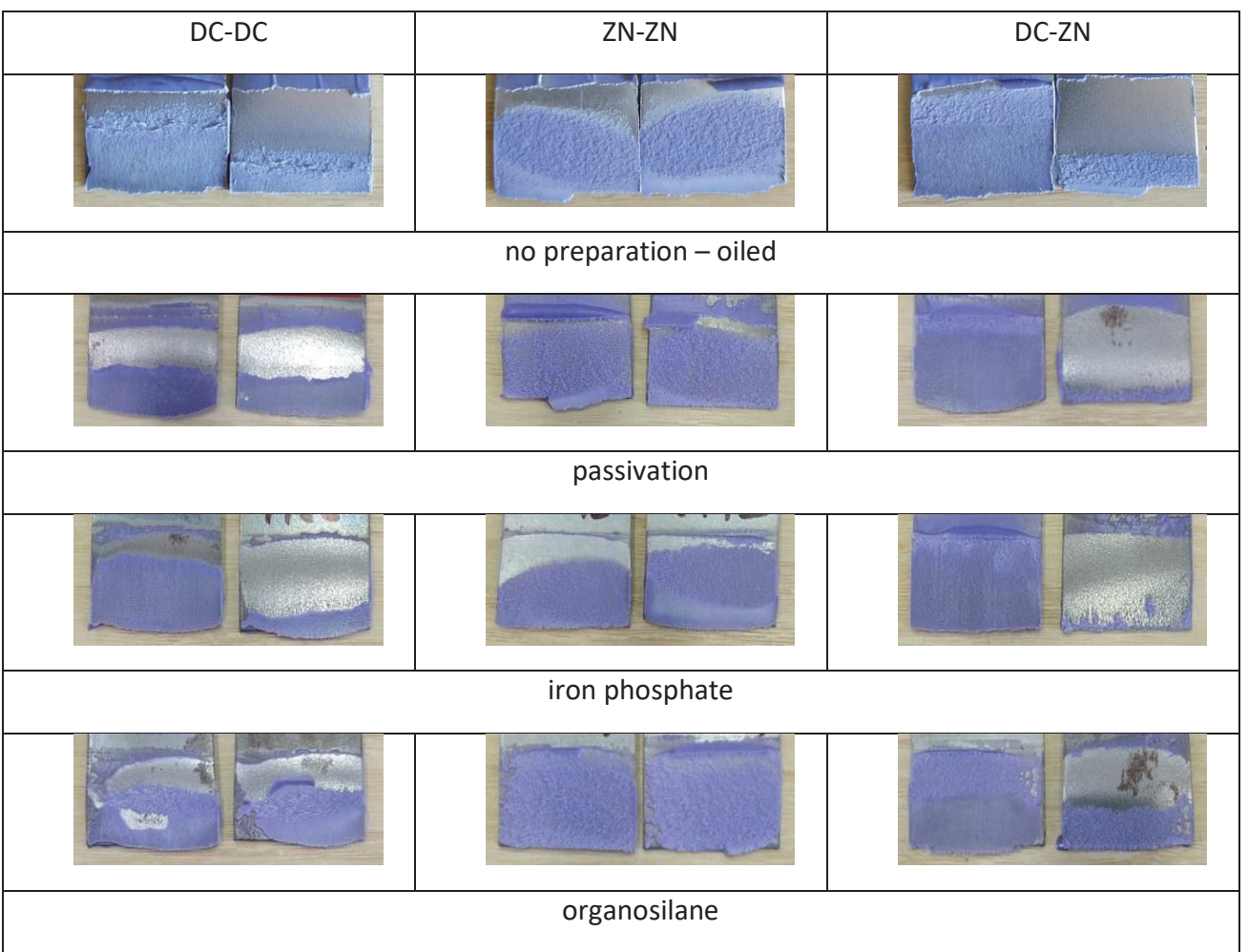


However, organosilane proved to be very promising in this research. It is formed on the surface from a clear aqueous solution that contains organomodified silica nanoparticles. When applied by immersion, the nanoparticles condense on the surface of the metal or conversion layer to form a gel colourless transparent invisible layer. Upon drying of the gel layer, a network of silicate compounds is formed, interconnected by siloxane bonds. The layer contains epoxy organic functional groups which are believed to be incorporated into the organic binder of the adhesive and to increase the loadbearing capacity of the joint. This assumption was confirmed in the experimental verification. The loadbearing capacity of the joint increased above the level of the yield strength of the stronger material. Organosilane can therefore be recommended for surface preparation before adhesive bonding of galvanized steels with higher strength.

\section{Conclusion}

The tested surface treatments created such conditions on the surface of the joined steels, that the adhesion of the adhesive to the surfaces was sufficient to form strong joints. In all cases, the loadbearing capacity of the joints exceeded the yield strength of the material with lower mechanical properties. This result can be attributed to the chemical modification of the surface as well as the morphology of the original surface of the galvanized material HX340LAD $+Z$, which is more suitable for mechanical anchoring of the adhesive compared to the morphology of deep-drawing steel DC04.

In the case of bonding materials with higher strength, surface treatment with organosilane has good preconditions for wider use. The application of organosilane is simple, rinse-free and low-cost - it does not require heating of process fluids, it takes place at room temperature, but it significantly increases the load-bearing capacity of adhesive joints through the formation of chemical bonds with the adhesive.

\section{Acknowledgements}

The contribution was created within solution of the project VEGA 1/0154/19: Research of the combined technologies of joining dissimilar materials for automotive industry.

\section{References}

1. Ni, J. et. al. (2020). Effect of adhesive type on mechanical properties of galvanized steel/SMC adhesive-bonded joints. International Journal of Adhesion and Adhesives, 97, 102482.

2. Ciupack, Y., Pasternak, H., Mette, Ch., Stammen, E., Dilger, K. (2017). Adhesive Bonding in Steel Construction - Challenge and Innovation. Procedia Engineering, 172, 186-193.

3. Dilger, K., Kreling. S. (2015). Adhesive bonding techniques for advanced high-strength steels (AHSS). Shome, M., Tumuluru, M., Welding and Joining of Advanced High Strength Steels (AHSS), Woodhead Publishing, 2015, p. 167179.

4. Szelag, P., Chocholoušek, J. MM spektrum, Č. 4, 2008 Železnaté fosfátování, from https://www.mmspektrum. com/clanek/zeleznate-fosfatovani.html, 25.11.2020

5. Pokorný, P. Tribotechnika 6/2012. Klasifikace fosfátových povlaků, from http://www.tribotechnika.sk/ tribotechnika-62012/klasifikace-fosfatovych-povlaku.html, 25.11.2020

6. Pokorný, P. (2013). Předpokládaná účinnost konverzních povlaků proti aktivaci zinkované oceli $\vee$ modelových pórových roztocích betonu. Koroze a ochrana materiálu, 57, 4, 115-126.

7. Tian, Y. et. al. (2020). Accelerated formation of zinc phosphate coatings with enhanced corrosion resistance on carbon steel by introducing a-zirconium phosphate. Journal of Alloys and Compounds, 831, 154906.

8. Wang, M. et. al. (2020). Corrosion resistance of black phosphorus nanosheets composite phosphate coatings on Q235 steel. Materials Chemistry and Physics, volume 250, 123056.

9. Hwang, E.H. et. al. (2019). Analysis on surface film formed on high-strength carbon steels in acidic phosphate solution and its relationship with localized corrosion in a 3.5\% NaCl solution. Journal of Materials Research and Technology, 8, 1, 1419-1426. 